\title{
Research of the influence of flue gas recirculation on the processes in the Itv furnace
}

\author{
Evgeny Tsibizov ${ }^{1, *}$, Boris Lebedev ${ }^{1}$, and Maria Cherckasova ${ }^{1}$ \\ ${ }^{1}$ National Research Tomsk Polytechnic University, 634050 Tomsk, Russia
}

\begin{abstract}
The combustion of solid low-grade fuel in LTV-boiler furnaces is a pressing research questions currently. The aim of this work is to study the influence of flue gas entering the process fully-the boiler furnace. The result of the calculation of the resulting distribution of temperatures and oxygen concentrations along the height of the furnace. The analysis of the obtained results.
\end{abstract}

\section{Introduction}

Low-temperature vortex combustion is a modern effective technology of using solid organic fuels. This method of burning and heating device for its implementation developed in St. Petersburg technical University [1].

The technology is based on the organizing principle of low-temperature vortex (NTV) solid fuel burning coarse grinding in the conditions of continuous circulation of the particles in a chamber furnace.

\section{Object of study}

In LTV-furnace with two zones of combustion. The vortex area is the volume of the lower furnace from the mouth of the furnace and to the burners. The flow combustion zone is located above the vortex area in the upper part of the furnace.

Temperature controls of gases in combustion chamber of steam boilers can be done in various ways. One of them is recirculation selected for the tail heating surfaces of flue gases.

\section{Air and Recirculation modes}

Aerodynamics of the vortex zone created by the interaction of two organized flows. The first stream is formed from the fuel-air mixture; the second stream consists of hot air. It is fed into the furnace through a system of bottom blowing. Flows directed towards each other and form a couple of forces. It creates a vortex motion in the lower part of the furnace [2].

* Corresponding author: TabakaevRB@tpu.ru 
Table 1. Feed rates of air and flue gases.

\begin{tabular}{|c|c|c|c|c|c|}
\hline \multirow{3}{*}{ Velocity } & \multirow[b]{2}{*}{$\begin{array}{l}\text { The } \\
\text { air }\end{array}$} & \multicolumn{4}{|c|}{ Recirculation of flue gases } \\
\hline & & $\begin{array}{l}\text { The upper } \\
\text { tier of } \\
\text { tertiary blast }\end{array}$ & $\begin{array}{c}\text { The lower } \\
\text { tier tertiary } \\
\text { blast }\end{array}$ & $\begin{array}{l}\text { The upper } \\
\text { layer of the } \\
\text { lower blast }\end{array}$ & $\begin{array}{l}\text { The lower layer } \\
\text { of the lower blast }\end{array}$ \\
\hline & $\mathrm{m} / \mathrm{s}$ & $\mathrm{m} / \mathrm{s}$ & $\mathrm{m} / \mathrm{s}$ & $\mathrm{m} / \mathrm{s}$ & $\mathrm{m} / \mathrm{s}$ \\
\hline $\mathrm{DHCp}^{1)}$ & 23 & 23 & 23 & 23 & 23 \\
\hline Primary & 30 & 30 & 30 & 30 & 30 \\
\hline Secondary & 40 & 40 & 40 & 40 & 40 \\
\hline Up.Tert.Bl. & 0.1 & 20 & 28 & 26.5 & 34 \\
\hline Low.Tert.Bl. & 35 & 30 & 15 & 30 & 35 \\
\hline Up.Low.B1. & 30 & 30 & 30 & 55.40 & 30 \\
\hline Low.Low.Bl. & 30 & 30 & 30 & 30 & 11.68 \\
\hline
\end{tabular}

1) DHCp - The dust feeding system of high concentration under pressure

\section{Temperature and oxygen distribution}

In the furnace of the investigated boiler is the selection of flue gas behind the heater. The proportion of recirculation is 0.15 , and the temperature at the point of selection is $160 \mathrm{C}$.

Evaluated the effect of recirculation gases on combustion processes. To allow comparison of the results obtained is maintained constant excess air in the furnace, equal to 1,2. Places the input gas recirculation and velocity are presented in table 1.

Graphics were constructed from the simulation results (fig. 1, 2). They represent the average values of flue gas temperatures and oxygen level at the height of the furnace depending on the introduction of recirculation gases.

In Fig. 1 shows the averaged horizontal cross-section of the temperature change of flue gases at altitude. The maximum temperature observed in the air mode in the vortex area at a height of $4.1 \mathrm{~m}$, and is $1698 \mathrm{~K}$. the Minimum temperature (1399) is observed in the vortex zone at the input of flue gases through the lower tier tertiary blowing. However, this regime is delaying the process of combustion, burning of fuel occurs outside the vortex zone, and the temperature in this zone of the furnace $(10-20 \mathrm{~m})$ than the other temperature regimes. At the exit of the furnace the maximum temperature is observed when the air mode is $1271 \mathrm{~K}$. the Minimum temperature is observed at the input of flue gases through the lower layer of the lower blast is $1231 \mathrm{~K}$.

In Fig. 2 shows averaged along the horizontal cross-section change in the concentration of oxygen in the flue gases at altitude. Peaks of concentrations observed in the inlet air, namely in the area of the burners and lower blast. However, when you enter the flue gas through the system of bottom blowing oxygen concentration in the lower part of the vortex is significantly reduced. The minimum value of concentration (of 0.002 ) is reached at a height of $6.6 \mathrm{~m}$ upon introduction of flue gases through the lower layer of the lower blast. The minimum concentration of oxygen (0.058) at the outlet of the furnace is observed when entering the flue gas through the upper tier tertiary blowing, and the maximum $(0.072)$ when entering gases through the lower layer of the lower blast. 


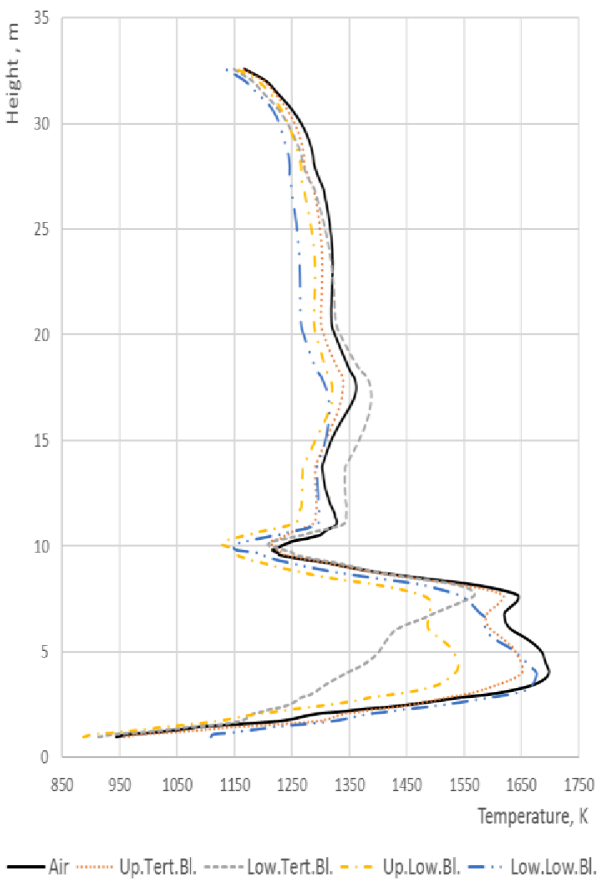

Fig. 1. The average temperature at the height of the furnace.

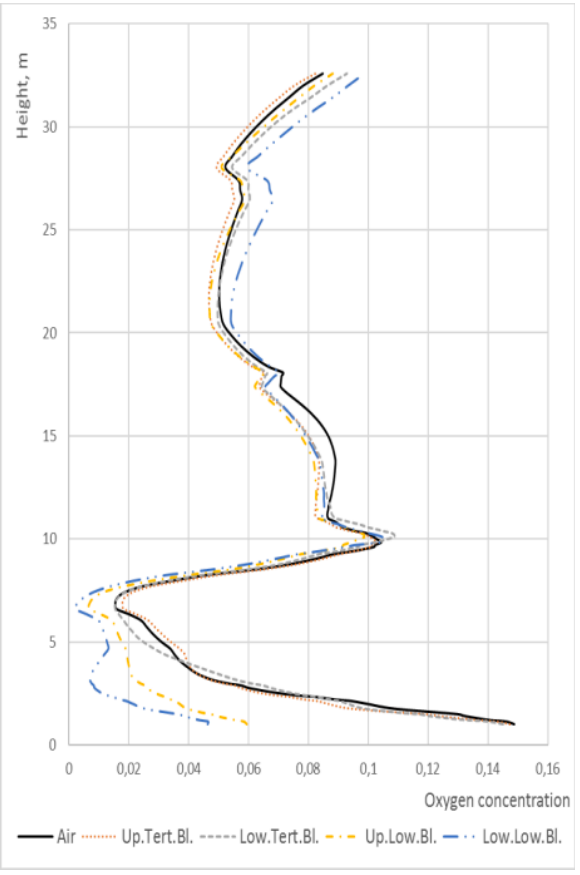

Fig. 2. Average values of oxygen concentration along the height of the furnace.

\section{Conclusions}

1) The temperature inside the investigated volume of the combustion chamber reaches the maximum value in the absence of recirculation gases.

2) The concentration of $\mathrm{O} 2$ in the lower part of the furnace is much lower when entering the flue gas through the channels of the lower blast than the other modes. The input of recirculation gases through the device of the tertiary blast has little effect on the concentration of oxygen in the vortex part of the furnace compared to the air mode.

\section{References}

1. P.S. Gergelizhiu, K.Y. Scherbakova, B.V. Lebedev, MATEC Web Conf. 23, (2015)

2. K.Y. Orlova, B. V. Lebedev, MAREC Web Conf. 92, (2017)

3. B.V. Lebedev, A.S. Zavorin, Bulletin of Tomsk Polytechnic University, 315, 15 (2009) [In Russian]

4. New modernized power-generating unit was put into service on Nazarovo state district power station. (Newslab.ru, 2013) [In Russian]

5. A.M. Bubenchikov, A.V. Starchenko Numerical modeling of aerodispersive mixings' dymanic and combustion in channels, 221 (1998), ISBN 5-7511-1004-8 [In Russian] 